\title{
Modulação do estado de polimerização in vitro dos filamentos intermediários em astrócitos pela fosforilação e proteína S100B
}

\author{
ERICA BORTOLI \\ JULIANA K. FRIZZO \\ Carlos Alberto Gonçalves
}

\section{Resumo}

Os filamentos intermediários representam um dos principais componentes do citoesqueleto de células eucarióticas. O monômero desses filamentos em astrócitos é a GFAP ("glial fibrillary acidic protein"), cuja polimerização é modulada aparentemente pela fosforilação e pela interação com uma proteína ligante de cálcio, a S100B. Neste estudo investigamos a polimerização in vitro da GFAP, usando um ensaio baseado na sedimentação induzida por imidazol/ alto magnésio. De fato, a GFAP solúvel (não polimerizada) aumentou em cerca de $25 \%$ na presença de S100B ou PKA (proteína cinase A). Estes dados sugerem que ambos os mecanismos possam estar atuando no ciclo de polimerização/despolimerização da GFAP em momentos e/ou situações diferentes afetando a plasticidade glial.

Palavras-chaves: GFAP, S100B, fosforilação protéica, plasticidade glial. 


\section{Abstract}

Intermediate filaments represent a major cytoskeleton constituent in eukaryotic cells. GFAP ("glial fibrillary acidic protein") is the monomer of these filaments in astrocytes and its polymerization is apparently modulated by phosphorylation and by interaction with $\mathrm{S} 100 \mathrm{~B}$, a calcium-binding protein. In this study we investigate in vitro polymerization of GFAP, using an assay based on imidazol/high magnesium-induced sedimentation. In fact, soluble GFAP (nonpolymerized) increased about $25 \%$ in presence of S100B or PKA (protein kinase A). These data suggest that both mechanisms could be acting in the cycle of polymerization/depolymerization of GFAP at different times and/or conditions, therefore affecting glial plasticity. Key words: GFAP, S100B, protein phosphorylation, glial plasticity.

Abreviações: GFAP, proteína glial fibrilar ácida; AMPc, AMP cíclico; PKA, proteína cinase dependente de AMPC; SDS-PAGE, eletroforese em gel poliacrilamida com dodecil sulfato de sódio.

\section{Introdução}

O $\mathrm{Ca}^{2+}$ exerce ampla atividade modulatória no sistema nervoso central e grande parte desta atividade ocorre via proteínas ligantes de $\mathrm{Ca}^{2+}$ como a calmodulina e $\mathrm{S100B}$. A proteína $\mathrm{S} 100 \mathrm{~B}$, estruturalmente um homodímero de $21 \mathrm{kDa}$ com sítios ligantes de $\mathrm{Ca}^{2+}$ do tipo "EF-hand", é expressa principalmente em astrócitos onde desempenha possivelmente diversas funções, incluindo a regulação do ciclo celular e do citoesqueleto. A atuação da S100B no citoesqueleto envolve ligação a proteínas modulatórias de microfilamentos, microtúbulos e filamentos intermediários (1-3).

A GFAP é a proteína que constitui, ao lado da vimentina, os filamentos intermediários dos astrócitos, sendo considerada um marcador destas células. Bianchi e colaboradores (4) mostraram que in vitro a S100B promove a despolimerização dos filamentos de GFAP, não só desfazendo filamentos pré-formados, como se ligando ao monômero e impedindo sua polimerização. Por outro lado, mostramos também in vitro que a $\mathrm{S} 100 \mathrm{~B}$ reduz a fosforilação da GFAP $(1,2)$. Entretanto, a relação direta entre estes dois eventos modulatórios da polimerização, fosforilação e presença de S100B, não foi estabelecida. 
Buscando investigar essa possível relação usamos neste trabalho um ensaio de sedimentação induzida por imidazol/alto magnésio, onde a fração não polimerizada de GFAP permanece solúvel e pode ser avaliada por eletroforese. Para confirmar o envolvimento da S100B com a fosforilação da GFAP e vimentina, estimulamos a fosforilação destas proteínas através da ativação de PKA por AMPc, em citoesqueleto de astrócitos.

\section{Material e Métodos}

Material. O material de cultura foi obtido da Gibco, exceto o soro bovino fetal (Cultilab). O $\gamma_{-3}{ }^{32}$ P-ATP foi proveniente da ICN. Os demais reagentes foram obtidos da Sigma. A GFAP purificada foi nos presenteada pelo Dr. Rosario Donato (Universidade de Perugia , Itália).

Cultura de astrócitos e Preparação do Citoesqueleto. Culturas primárias de astrócitos foram preparadas como previamente descrito $(5,6)$. Os hipocampos de ratos Wistar neonatos, provenientes do Biotério do Departamento de Bioquímica, foram removidos e colocados em uma solução salina balanceada livre de $\mathrm{Ca}^{2+}$ e $\mathrm{Mg}^{2+}$, $\mathrm{pH} 7,4$, contendo: $137 \mathrm{mM}$ de $\mathrm{NaCl} ; 5,36 \mathrm{mM}$ de $\mathrm{KCl} ; 0,27 \mathrm{mM}$ de $\mathrm{Na}_{2} \mathrm{HPO}_{4}$ e $6,1 \mathrm{mM}$ de glicose. O tecido foi dissociado mecanicamente através da passagem por uma pipeta Pasteur. A suspensão de células foi centrifugada a $1000 \mathrm{rpm}$ por $5 \mathrm{~min}$. O sobrenadante foi descartado e o precipitado ressuspenso em meio de cultura $\mathrm{pH} 7,6$ contendo: $1 \%$ de DMEM ("Dulbecco's modified Eagle's medium"), $8,39 \mathrm{mM}$ de tampão HEPES, $23,8 \mathrm{mM}$ de $\mathrm{NaHCO}_{3}, 0,1 \%$ de fungizona, $0,032 \%$ de garamicina e $10 \%$ de soro fetal bovino. As células foram semeadas numa densidade de 1,5 × 105 células $/ \mathrm{cm}^{2}$ em placas de 24 poços pré-tratadas com poli-L-lisina. As culturas foram mantidas em atmosfera de $5 \%$ de $\mathrm{CO}_{2} / 95 \%$ de ar a $37^{\circ} \mathrm{C}$ até atingirem a confluência (14 dias). A fração citoesquelética Tritoninsolúvel foi preparada de acordo com Harrison e Mobley, 1992 (7). As células foram raspadas e homogeneizadas em tampão Tris $(\mathrm{pH}$ 7,0) contendo: $50 \mathrm{mM}$ de Tris- $\mathrm{HCl}, 2 \mathrm{mM}$ de EDTA, $2 \mathrm{mM}$ de PMSF (fluoreto de fenilmetilsulfonila), $1 \mathrm{mM}$ de DTT (ditiotreitol) e $0,5 \%$ de Triton $\mathrm{X}-100$. Depois de $30 \mathrm{~min}$ no gelo, as amostras foram centrifugadas a $15000 \times \mathrm{g}$ por $15 \mathrm{~min}$. O precipitado foi ressuspenso em tampão Tris e novamente centrifugado. O precipitado foi ressuspenso então em $20 \mathrm{mM}$ de Tris- $\mathrm{HCl}(\mathrm{pH} 7,4)$ para obter-se uma concentração final de $2 \mathrm{mg}$ de proteína $/ \mathrm{mL}$, medida pelo método de Lowry. 
Ensaio de fosforilação de proteínas e eletroforese: 0 ensaio de fosforilação continha num volume final de $50 \mathrm{~mL}: 10 \mathrm{mM}$ de Tris- $\mathrm{HCl}(\mathrm{pH} 7,4), 12 \mu \mathrm{M}$ de ATP $\left(5 \mu \mathrm{Ci} \gamma^{-32} \mathrm{P}\right.$-ATP), $10 \mu \mathrm{g}$ de proteína do citoesqueleto e $1 \mu \mathrm{M}$ de $\mathrm{MgCl}_{2}$. AMPc e S100B eram adicionados nas concentrações de $50 \mu \mathrm{M}$ e de $5 \mu \mathrm{M}$, respectivamente. A reação foi iniciada pela adição de $\gamma^{32} \mathrm{P}$-ATP e mantida a $30^{\circ} \mathrm{C}$ por $30 \mathrm{~min}$, quando foi parada pela adição de $500 \mu \mathrm{L}$ de ácido tricloroacético. As amostras foram deixadas em gelo por 30 min e centrifugadas a 15000 $x \mathrm{~g}$ por $10 \mathrm{~min}$. O precipitado foi lavado uma vez com ácido tricloroacético $4 \%$ e com etanol $80 \%$. Depois as amostras foram dissolvidas em $60 \mu \mathrm{L}$ de tampão de eletroforese Tris-SDS contendo $4 \%$ de SDS, $5 \%$ de mercaptoetanol, $2 \mathrm{mM}$ de EDTA, $50 \mathrm{mM}$ de Tris$\mathrm{HCl}, \mathrm{pH} 6,8$. As amostras foram analisadas em 10\% de SDS-PAGE. Os géis secos foram expostos a filmes de raios- $X$. A quantificação da fosforilação de GFAP e vimentina foi feita por densitometria.

Ensaio de sedimentação da GFAP: Os ensaios de sedimentação foram realizados conforme descrito previamente (8-10). GFAP bovina purificada (4) na concentração de $0,5 \mathrm{mg} / \mathrm{mL}$, foi preparada em $10 \mathrm{mM}$ Tris- $\mathrm{HCl}(\mathrm{pH} 7,2), 0,1 \mu \mathrm{M}$ de $\mathrm{MgCl}_{2}, 1 \mathrm{mM}$ de DTT num volume final de $90 \mu \mathrm{L}$. A pré-incubação a $30^{\circ} \mathrm{C}$, durante $2 \mathrm{~h}$, foi feita: (a) com adição de ATP $(0,2 \mathrm{mM})$ e PKA (3 unidades, PKA Sigma); (b) S100B (5 $\mu \mathrm{M})$ (c) ATP, PKA e S100B; e (d) sem adições (basal). Após esta etapa foram adicionados às amostras $10 \mu \mathrm{L}$ de tampão imidazol- $\mathrm{HCl} 1 \mathrm{M}, \mathrm{pH} \mathrm{6,8}$, contendo $10 \mathrm{mM}$ de $\mathrm{MgCl}_{2}$, para induzir a sedimentação da GFAP, durante um período de incubação de $30 \mathrm{~min}$. Então as amostras foram centrifugadas a $13000 \mathrm{x} \mathrm{g}$ por

30 min. O sobrenadante - contendo a GFAP não polimerizada - foi transferido para um tubo eppendorf contendo $50 \mu \mathrm{L}$ de ácido tricloroacético $30 \%$ e mantido durante a noite em gelo. As amostras foram centrifugadas a 13000 x g por $15 \mathrm{~min}$. O precipitado foi lavado duas vezes com etanol $80 \%$ gelado e dissolvido em $60 \mu \mathrm{L}$ de tampão de eletroforese descrito acima. As amostras foram submetidas à eletroforese unidimensional (SDS-PAGE 10\%). O gel foi corado com azul de Comassie e as bandas correspondentes a GFAP foram quantificadas por densitometria pelo programa Optiquant.

\section{Resultados}

Inibição da fosforilação de GFAP por S100B. A S100B causou uma inibição da fosforilação da GFAP e vimentina estimulada por AMPc. Este efeito inibitório da S100B sobre a fosforilação da 
GFAP e vimentina pode ser atribuído à ligação da S100B diretamente nos sítios de fosforilação destas proteínas, possivelmente bloqueando $o$ acesso de proteínas cinases (Figura 1).

Fosforilação e $S 100 B$ afetam a sedimentação da GFAP. Considera-se que o conteúdo de GFAP, não sedimentado com a incubação com imidazol e alto magnésio, corresponda à fração não polimerizada da GFAP. Os ensaios mostraram que houve um aumento significativo (cerca de $25 \%$ ) tanto na presença de S100B, quanto na presença de PKA e ATP. Entretanto, observou-se que a S100B e a fosforilação da GFAP (estimuladas pela adição de PKA e ATP) não têm um efeito aditivo. De fato, inesperadamente, não se observa um efeito sobre a sedimentação quando S100B, PKA e ATP são adicionados juntos (Figura 2).

\section{Discussão}

Nossos estudos confirmam que a $\mathrm{S} 100 \mathrm{~B}$ tem um efeito inibitório sobre a fosforilação da GFAP. A S100B se liga à GFAP em uma seqüência crítica de polimerização chamada de "RP box motif", localizada na porção $\mathrm{N}$-terminal da proteína (11). Em ratos esta seqüência apresenta três locais possiveis de serem fosforilados, as serinas $36 / 38$ e a treonina 41 (12). Os outros locais de fosforilação da GFAP são a treonina 7 e as serinas 8/12/16. A PKA e a cinase dependente de calmodulina Tipo II fosforilam a GFAP nos resíduos 716, e nos resíduos da "RP box motif". Portanto, é possível que a S100B diminua a fosforilação da GFAP pela ligação na sua porção $\mathrm{N}$-terminal. Por outro lado, outro local de ligação da S100B foi encontrado na hélice 2A da GFAP (13). Assim, a S100B pode inibir a polimerização da GFAP pela ligação neste local, bloqueando a elongação dos protofilamentos de GFAP. Este evento parece ser independente da inibição da fosforilação da GFAP S100B-dependente, implicando que a S100B pode ser capaz de ligar-se tanto na GFAP fosforilada, quanto na GFAP não fosforilada.

$O$ ensaio de sedimentação da GFAP purificada, com o tampão imidazol-magnésio, mostrou que tanto a adição de S100B quanto a fosforilação por PKA dificultou a polimerização da GFAP, aumentando sua presença na fração solúvel. Isoladamente $S 100 \mathrm{~B}$ ou a fosforilação induzida por PKA causaram uma despolimerização (ou evitaram a polimerização) na ordem de $25 \%$. Ao contrário, quando PKA e S100B foram adicionadas juntas, esse aumento na despolimerização desapareceu. 


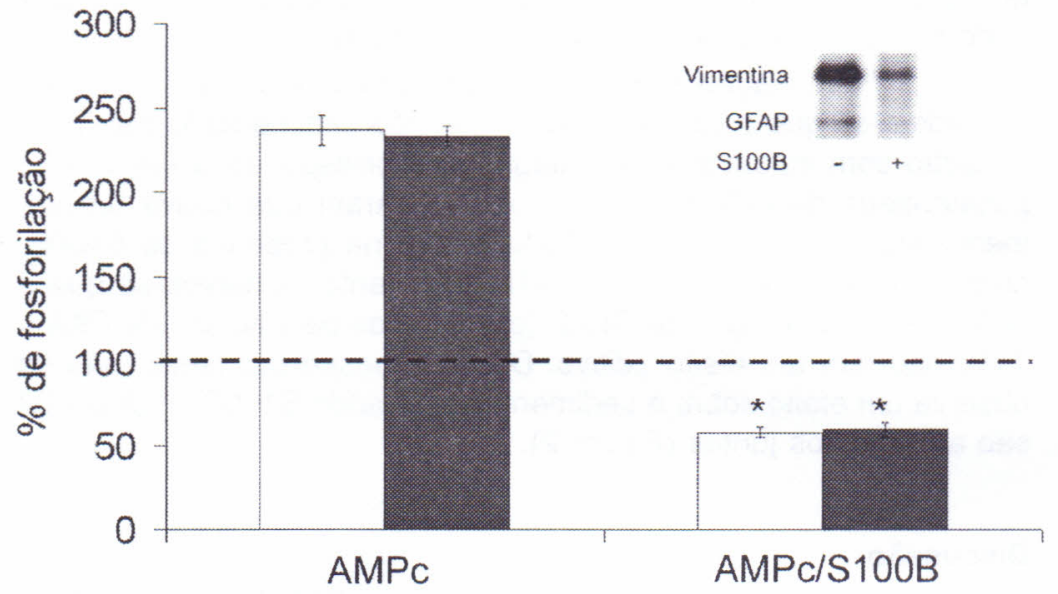

Fig. 1. Inibição da fosforilação de GFAP e vimentina por S100B. Amostras de citoesqueleto foram incubadas com $\gamma$ - ${ }^{32}$ P-ATP e a fosforilação de proteínas foi analisada por SDS-PAGE. AMPc e S100B foram adicionados numa concentração de $50 \mu \mathrm{M}$ e $5 \mu \mathrm{M}$, respectivamente. A fosforilação da GFAP e vimentina foi quantificada pelo programa Optiquant. A linha pontilhada (100\%) corresponde a fosforilação basal das proteínas. As barras brancas correspondem a vimentina e as barras pretas a GFAP. Estes valores representam a média $( \pm E P)$ de 3 experimentos independentes. ${ }^{*}$ Significativamente distinto da fosforilação de proteínas estimulada por AMPc $(P<0,01)$. Inserido a direita, observa-se as bandas correspondentes às proteínas vimentina e GFAP. 


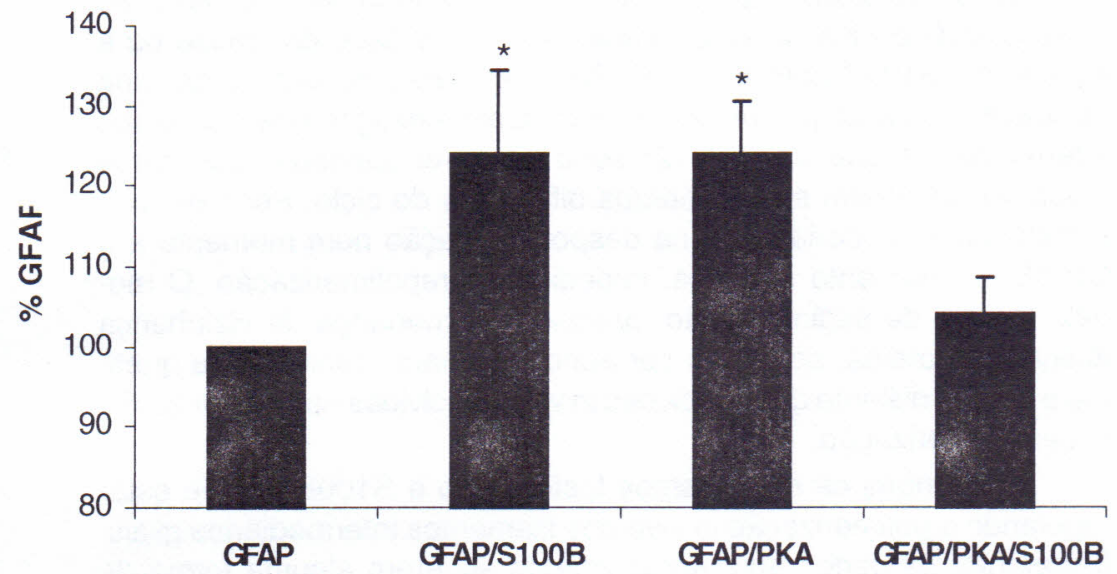

Fig. 2. Conteúdo de GFAP no sobrenadante após a indução da sedimentação. GFAP $(0,5 \mathrm{mg} / \mathrm{mL})$ foi incubada com $5 \mathrm{mM}$ de $\mathrm{S} 100 \mathrm{~B}$ e/ou $3 \mathrm{U}$ de PKA e 0,2 mM de ATP, em $\mathrm{pH}=7,2$ e então submetida ao ensaio de sedimentação pela adição de tampão Imidazol-Mg $(\mathrm{pH}=6,8)$. O contéudo de GFAP no sobrenadante obtido foi analisado por eletroforese unidimensional e o gel corado com azul de Comassie. As bandas foram quantificadas pelo programa Optiquant. Estes valores representam a média $( \pm E P)$ de 5 experimentos independentes $\left({ }^{*} P<0,05\right)$. 
Considerando que tanto a S100B quanto a fosforilação (via PKA) provocaram a despolimerização da GFAP (ou impediram a polimerização), torna-se complexa interpretação dos dados conjuntamente. Uma possibilidade, embora muito remota, seria a interação entre S100B e PKA "in vitro", impedindo a atividade da cinase ou a ligação da S100B com a GFAP. Por outro lado, considerando uma atividade cíclica de polimerização e despolimerização dos filamentos intermediários que ocorre (12) seria possivel conceber que estes mecanismos atuem em momentos diferentes do ciclo. Por exemplo, a fosforilação poderia atuar na despolimerização num momento e a S100B no momento seguinte, impedindo a repolimerização. O modelo in vitro de sedimentação, baseado na mudança da vizinhança iônica da proteína, pode não ser adequado para resolver esta questão e parece distante das condições in vivo envolvidas na polimerização e despolimerização.

Ambos os mecanismos fosforilação e S100B podem estar regulando a polimerização in vivo dos filamentos intermediários gliais. Entretanto, os dados aqui apresentados sugerem alguma forma de interferência entre os dois mecanismos no modelo in vitro utilizado. É interessante também mencionar que a desfosforilação da GFAP, com fosfatase alcalina, reduziu levemente a capacidade de polimerização in vitro da GFAP (8).

Nossos dados reforçam o possível papel da proteína S100B e da fosforilação na regulação do citoesqueleto glial, particularmente dos filamentos intermediários. Entretanto, ainda é limitada nossa compreensão sobre o papel dos diversos sítios fosforilados na GFAP ou mesmo dos sítios de interação com a S100B.

\section{Apoio financeiro}

Este trabalho foi financiado pelo CNPq, pela FAPERGS e pelo Programa Integrado de Bolsas de Iniciação Científica da Universidade Federal do Rio Grande do Sul (PIBIC/UFRGS). 


\section{Referências bibliográficas}

1 ZIEGLER, D. R., INOCENTE, C. E., LEAL, R. B., RODNIGHT, R. AND GONÇALVES, C. A. The S100B protein inhibits phosphorylation of GFAP and vimentin in a cytoskeletal fraction from immature rat hippocampus. Neurochem. Res., 1998, 23:1259-1263.

2 KARL, J., TRAMONTINA, F., LENGYEL, I., KLEIN, M., RODNIGHT, R. AND GONÇALVES, C. A. The calcium-dependent inhibition of fibrillary acidic protein phosphorylation by $\mathrm{S} 100 \mathrm{~B}$ in primary cultures of astrocytes. J. Neurochemistry., 2001, 78 (Suppl):93.

3 DONATO, R. Functional roles of $\mathrm{S} 100$ proteins, calcium-binding proteins of the EF-hand type. Biochim. Biophys. Acta, 1999, 1450:191231.

4 BIANCHI, R., GIAMBANCO, R. AND DONATO, R. S100 protein, but not calmodulin, binds to the glial fibrillary acidic protein and inhibits its polymerization in a $\mathrm{Ca}^{2+}$-dependent manner. J. Biol. Chem., 1993, 268:12669-12674.

5 KARL, J., GOTTFRIED, C., TRAMONTINA, F., DUNKLEY, P., RODNIGHT, R. AND GONÇALVES, C. A. GFAP phosphorylation studied in digitonin-permeabilized astrocytes: standardization of conditions. Brain Res., 2000, 853:32-40.

6 GOTTFRIED, C., VALENTIM, L., SALBEGO, S., KARL, J., WOFCHUK, S. T., RODNIGHT, R. Regulation of protein phosphorylation in astrocyte cultures by external calcium ions: specific effects on the phosphorylation of glial fibrillary acidic protein (GFAP), vimentin and heat shock protein 27 (HSP27). Brain Res., 1999, 833:142-149.

7 HARRISON, B. C. AND MOBLEY, P. L. Phosphorylation of glial fibrillary acidic protein and vimentin by cytoskeletal-associated intermediate filament protein kinase activity in astrocytes. J. Neurochem., 1992, 58:32-327.

8 YANG, Z. W. AND BADITCH, J. A. Factors modulating filament by bovine glial fibrillary acidic protein, the intermediate filament component of astroglial cells. Biochemistry, 1988, 27:7045-7050.

9NAKAMURA, Y., TAKEDA, M. AND NISHIMURA, T. Dynamics of bovine glial fibrillary acidic protein phosphorylation. Neurosc. Lett., 1996, 205: 91-94.

1ONAKAMURA, Y., TAKEDA, M., ANGLIDES, K. J., TADA, K., HARIGUSHI, S. AND NISHIMURA, T. Assembly, disassembly, and exchange of glial fibrillary acidic protein. Glia, 1991, 4:101-110. 
11 BIANCHI, R., GARBUGLIA, M., VERZINI, M., GIAMBANCO, I., IVANENKOV, V. V., DIMLICH, R. V. W., JAMIESON, JR. G. A. AND DONATO, R. S-100 (alpha and beta) binding peptide (TRTK-12) blocks S-100/GFAP interaction: identification of a putative S-100 target epitope within the head domain of GFAP. Biochim. Biophys. Acta, 1996, 1313:258-267.

12 RODNIGHT, R., GONÇALVES, C. A., WOFCHUK, S. T. AND LEAL, R. Control of the phosphorylation of the astrocyte marker glial fibrillary acidic protein (GFAP) in the immature rat hippocampus by glutamate and calcium ions: possible key factor in astrocytic plasticity. $\mathrm{Br}$. J. Med. Biol. Res., 1997, 30:325-338.

13 MCCLINTOCK, K. A. AND SHAW, G. S. A logical sequence search for S100B target proteins. Protein Sci., 2000, 9:2043-2046.

ERICA Bortoli Departamento de Bioquímica JuLIANA K. Frizzo Departamento de Bioquímica Carlos Alberto Gonçalves casg@ufrgs.br Departamento de Bioquímica Instituto de Ciências Básicas da Saúde Universidade Federal do Rio Grande do Sul Porto Alegre, RS - Barsil 